\title{
De Teresa Ochoa, Adriana (Coord.). (2019). Horizontes teóricos y críticos en torno a la figura autoral contemporánea. UNAM.
}

\author{
José Emilio GonzÁlez Calvillo \\ Facultad de Filosofía y Letras ${ }^{1}$ \\ Universidad Nacional Autónoma de México | México
}

1 Estudiante de la Licenciatura en Lengua y Literatura Modernas (Letras Inglesas)

$\coprod$ a escritura, práctica con la cual se asocia a la literatura, posee cierta cualidad misteriosa: los vocablos que se conforman mediante la unión de grafías son sólo recipientes de una ausencia, de algo que se evoca en ese acto de nombrar, pero que no está ahí. Cuando, a su vez, las palabras se articulan para la creación de textos literarios y a éstos se les vincula con el nombre propio de quien firma por ellos, el misterio crece: ¿qué relación guarda el artefacto estético con el sujeto empírico que lo produce? De esta y otras tantas interrogantes afines se ocupan los estudios sobre la autoría. A pesar de que, en su insigne ensayo de 1967, Barthes condenara a muerte al autor, esta problemática no deja de suscitar discusiones trascendentales, tanto en la literatura como en otras disciplinas. El paso del tiempo ha demostrado que la figura autoral, junto con otros objetos dados por muertos como dios y el arte en épocas previas, no han desaparecido sino, más bien, han sido "desplazados, reubicados, destituidos, descentralizados o deconstruidos" (García Hubard, 2019: 55). El libro electrónico Horizontes teóricos y críticos en torno a la figura autoral contemporánea, coordinado por Adriana de Teresa Ochoa y publicado en 2019 por la Facultad de Filosofía y Letras de la Universidad Nacio- nal Autónoma de México, da cuenta de todas estas mutaciones por las que el concepto de autoría ha pasado, mediante la diversidad y lucidez de los ensayos que lo componen.

El libro consta de doce artículos escritos por académicas de México, España, Noruega y Venezuela; éstos se distribuyen en tres apartados. Asimismo, varios de los textos fueron presentados en una primera versión en un coloquio del mismo nombre que aconteció en octubre de 2015 en la institución que los publica. En la primera parte de la introducción, Adriana de Teresa Ochoa, quien en 2010 coordinó el libro Circulaciones: trayectorias del texto literario, sienta el terreno conceptual e histórico al trazar una sucinta genealogía sobre la noción de autor. Esta acepción surge de forma incipiente en el Renacimiento - con Montaigne como figura clave-, se consolida con la revolución estética e ideológica del Romanticismo, y encuentra en la conferencia de Barthes el punto de anclaje para las discusiones sobre este asunto en las décadas posteriores. En la segunda parte, De Teresa Ochoa resume los criterios que agrupan las tres secciones, así como cada uno de los textos.

La sección inaugural, "Tras las huellas del autor(a)", es la más extensa y posee un carácter eminentemente teórico. En ella se enmarca "La 
muerte del autor" en la historia de la crítica literaria europea, particularmente la francesa, y se exponen diferentes lecturas que se le han dado con el fin de proponer nuevas relaciones o de establecer otras poco exploradas, como aquella que se sostiene con el pensamiento de Jacques Derrida. La sección, además, aborda problemas como el papel que la autoría representa para la crítica feminista, o como la escisión que el autor suele tener con su comunidad y la necesidad de su reincorporación. Los ensayos de la segunda parte, "De máscaras y mediaciones", discuten ciertas instancias que desafían y ponen en duda al Autor (con mayúscula), pero que al mismo tiempo contribuyen a su construcción. Así, nociones como la falsificación (y sus respectivas variantes), la traducción, la crítica literaria y el testimonio son exploradas como circunstancias de la producción textual en las que se debe hablar tanto de posibles autores/as en sí, como del papel indispensable que éstos/as juegan para la edificación del escritor o escritora como figura autoral. Finalmente, el apartado "El Autor(a) en escena” es la puesta en práctica de varias de las aproximaciones teóricas que se exploran previamente, a partir de los estudios de caso sobre la escritura autobiográfica de Octavio Paz, las formas en las que se relacionan el novelista irlandés John Banville y su alter ego escritural Benjamin Black, y el papel que juegan las lecturas en voz alta de Coral Bracho para su construcción como autora.

Dentro de las ideas conductoras que atraviesan los ensayos de Horizontes teóricos, hay tres que me interesa señalar: la propuesta de la autoría como creación colectiva, el amplio panorama histórico que el libro abarca y las implicaciones del desarrollo tecnológico para esta materia. La primera se desprende de los títulos de dos apartados: "De máscaras y mediaciones" y "El Autor(a) en escena”. En ellos yace un léxico teatral ${ }^{2}$ que da

2 A estos dos habría que sumarles el título del ensayo de Julia Constantino, "Máscaras provisionales: sobre traducción, autoría y construcción de figuras autorales", para reforzar el punto. cuenta del carácter artificial y performático que resulta ser la figura autoral, así como del cariz eminentemente colectivo de la autoría, al emparentarla con el arte dramático. En palabras de Julia Constantino (2019), ésta figura se construye "en comunidad, como parte y resultado de una serie de sistemas que entran en contacto y siempre están en movimiento y transformación, donde podemos cuestionar la idea de cualquier tipo de sujeto como dueño del significado, para pasar a modalidades colectivas, fragmentarias, temporales, provisionales, performativas y plurales de construcción de textos, textualidades y figuras autorales" (163) Así, aunque el culto al autor es resultado de aquél que se le profesa al individuo, lo cierto es que para que éste exista es necesaria la participación de otros y otras. Siguiendo con la analogía teatral, pese a que en toda obra haya papeles protagónicos, debe haber papeles secundarios, vestuaristas, maquillistas y tramoyistas, para que ésta pueda realizarse a cabalidad. En el terreno meramente literario, para que exista el autor debe haber traductores, editores, críticos/as y, por supuesto, lectores.

La relevancia de la colectividad que plantea este libro es, a un tiempo, diagnóstico de un fenómeno y propuesta metodológica renovadora dentro de su campo: en ella subyace la idea de que revisar el asunto de la autoría posibilita transformaciones dentro de la literatura. Esto sucede gracias a que "la figura del autor siempre está refractada por el prisma de las voces de terceros que, $a$ posteriori, interactúan y constituyen la memoria colectiva que llamamos historia literaria" (Artigas Albarelli, 2019: 184). En ese sentido, esa historia literaria se ilustra a lo largo de Horizontes teóricos gracias a los recorridos que trazan textos como los de Pimentel, García Hubard y Toril Moi acerca de las diferentes aproximaciones que se han hecho sobre el autor y la autora, que, al leerlas en conjunto, amplían y complejizan esa historia; o bien, en el acercamiento contemporáneo que se hace a figuras no del todo coetáneas, como en el texto de González Treviño sobre los falsificadores ingle- 
ses del siglo XVIII. De igual manera, el estudio de múltiples géneros literarios (poesía, ensayo, testimonio) y de figuras tan diversas y contrastantes como Octavio Paz, Rigoberta Menchú e, incluso, Frida Kahlo - a partir del análisis que Eleonora Cróquer hace sobre los diarios de la pintora mexicana- evidencia la fértil pluralidad de estudiar la autoría. La historia literaria, entonces, se parece más a una espiral que a una línea e incorpora no sólo a los/as artistas que crean, sino también a quienes la consumen y la piensan.

El tema de la tecnología resulta trascendental para Horizontes teóricos desde su existencia material misma, pues éste es un libro exclusivamente electrónico y posee particularidades como un código QR que redirige a un video en YouTube donde la coordinadora hace una presentación del texto. Esto ejemplifica perfectamente "la [...] transformación que ha significado el desarrollo de las nuevas tecnologías, las cuales han creado formas inéditas de producción, circulación y apropiación de lo escrito" en las cuales "nociones como las de autor quedan en entredicho o, [...], dan lugar a nuevas acepciones y modalidades de interacción" (De Teresa Ochoa, 2019: 17). Es decir, ya no se trata solamente del libro impreso en papel, sino de la presencia de otros soportes sobre los que la textualidad recae. Al respecto, empero, el libro presenta ejemplos escasos, pero que dan una idea y abren el horizonte para estudios futuros. El primero está estrictamente vinculado con "las técnicas de estilometría digital, combinadas con psicolingüística” (González Treviño, 2019: 146), las cuales permiten comprobar si tal o cual obra fue escrita por un autor o no y cómo esto transforma la crítica literaria. El segundo se trata de la incorporación de "formas y formatos expandidos" (González Aktories, 2019: 253), tales como el sitio web del complejo seudónimo de John Banville o las "lecturas grabadas en estudio [...] editadas en CD o accesibles a través de podcasts" (253) de Coral Bracho, para la interpretación de sus respectivas obras.
En suma, los ensayos en conjunto conforman una visión panorámica sobre la autoría, que demuestran lo heterodoxo y problemático que ésta resulta ser. Horizontes teóricos y críticos en torno a la figura autoral contemporánea es didáctico y especializado a un tiempo: puede funcionar para esclarecer la lectura de "La muerte del autor", para acercarse a discusiones de densidad como el del lugar autoral en Ła Cultura [sic.], o para hallar bibliografía acerca de autores/as en específico. Lo cierto es que el libro resulta pertinente y apasionante acerca de este fenómeno literario y su lectura suscita nuevas formas de vincularse con la literatura.

\section{Referencias bibliográficas}

Artigas Albarelli, Irene María. (2019). "Imágenes de autor y curiosidades polifónicas: refracciones a Roland Barthes y William Carlos Williams". En Adriana de Teresa Ochoa (Coord.), Horizontes teóricos y críticos en torno a la figura autoral contemporánea (pp. 167-187). UNAM.

Constantino, Julia. (2019). "Máscaras provisionales: sobre traducción, autoría y construcción de figuras autorales". En Adriana de Teresa Ochoa (Coord.), Horizontes teóricos y críticos en torno a la figura autoral contemporánea (pp. 151-165). UNAM.

De Teresa Ochoa, Adriana. (2019). "Introducción". En Adriana de Teresa Ochoa (Coord.), Horizontes teóricos y críticos en torno a la figura autoral contemporánea. UNAM.

García Hubard, Gabriela. (2019). "Muerte y deconstrucción del autor: Barthes / Derrida". En Adriana de Teresa Ochoa (Coord.), Horizontes teóricos y críticos en torno a la figura autoral contemporánea. UNAM. 
GonzÁlez AkTories, Susana. (2019). "La dimensión sonora de la poesía y su relación con la figura autoral. Un acercamiento a partir de Agua de bordes lúbricos' leído por Coral Bracho en viva voz". En Adriana de Teresa Ochoa (Coord.), Horizontes teóricos y críticos en torno a la figura autoral contemporánea (pp. 251-295). UNAM.
González Treviño, Ana Elena. (2019). "Pruebas de paternidad textual: la falsificación literaria y la construcción del valor autoral". En Adriana de Teresa Ochoa (Coord.), Horizontes teóricos y críticos en torno a la figura autoral contemporánea (pp. 131-150). UNAM.

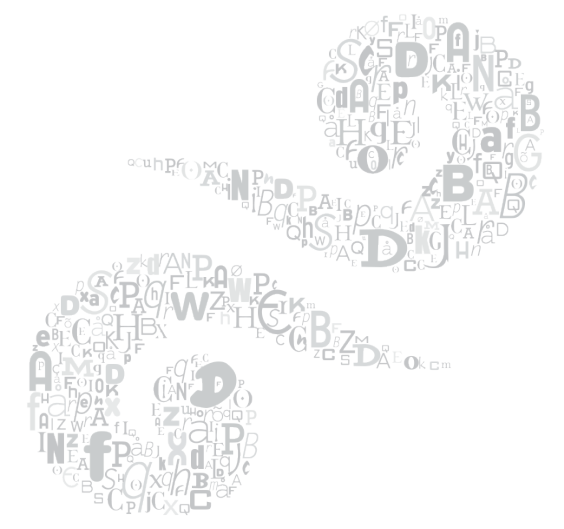

